Research, Society and Development, v. 9, n. 12, e45691211237, 2020

(CC BY 4.0) | ISSN 2525-3409 | DOI: http://dx.doi.org/10.33448/rsd-v9i12.11237

\title{
Alimentação saudável sob o olhar da Educação Ambiental
}

Healthy diet under the perspective of Environmental Education

Alimentación saludable desde la perspectiva de la Educación Ambiental

Recebido: 16/12/2020 | Revisado: 24/12/2020 | Aceito: 27/12/2020 | Publicado: 29/12/2020

Lorena Almeida Vieira

ORCID: https://orcid.org/0000-0002-0147-2996

Universidade Federal do Oeste do Pará, Brasil

E-mail: lore_vieira@yahoo.com.br

Maria Mirtes Cortinhas dos Santos

ORCID: https://orcid.org/0000 -0003-4921-7713

Universidade Federal do Oeste do Pará, Brasil

E-mail: mmcortinhas@gmail.com

Thiago Almeida Vieira

ORCID: https://orcid.org/0000 -0001-9926-2606

Universidade Federal do Oeste do Pará, Brasil

E-mail: Thiago.vieira@ufopa.edu.br

Jorgiene dos Santos Oliveira

ORCID: https://orcid.org/0000-0002-0899-0737

Universidade Federal do Oeste do Pará, Brasil

E-mail: jorgieneso3@gmail.com

Helionora da Silva Alves

ORCID: https://orcid.org/0000 -0003-2118-5502

Universidade Federal do Oeste do Pará, Brasil

E-mail: helionora.alves@ufopa.eu.br

\section{Resumo}

O desenvolvimento hegemônico no campo, que hoje se define pela matriz ideológica do agronegócio, tem como base principal a monocultura e uso de agrotóxicos, com objetivo de aumentar a produção de alimentos com o discurso de atender a demanda para a população mundial. Porém, várias problemáticas surgiram devido a essa lógica de produção, como danos irreversíveis ao meio ambiente, problemas na saúde humana, perdas em campo, desperdício de alimentos, entre outros. Considerando esse contexto, é crescente na sociedade reflexões, 
discussões e ações que visem a conservação do ambiente, e um importante instrumento para a sensibilização em prol da utilização racional dos recursos presentes na natureza, é a Educação Ambiental. Por meio desta, é possível proporcionar a articulação entre diferentes áreas do conhecimento, no sentido de se levar conhecimentos e reflexões, apresentar experiências e sensibilizar quanto a necessidade de preservar, conservar e recuperar áreas, dentre muitos outros aspectos ligados à relação estabelecida entre ser humano e a natureza. Nessa perspectiva, este artigo teve como objetivo analisar como a Educação Ambiental pode contribuir na promoção da alimentação saudável, apontando os reflexos do processo de produção alimentar no desenvolvimento sustentável. Dessa forma, realizou-se uma revisão da literatura acerca de Educação Alimentar e Alimentação Saudável. Os resultados dos estudos foram analisados, propiciando uma síntese sobre a temática em questão. Constatou-se que alguns autores apontam êxito da Educação Ambiental como instrumento para sensibilizar pessoas a um espírito ecológico, sendo assim, é importante instrumento na tentativa de minimizar os impactos negativos decorrentes da alimentação.

Palavras-chave: Sistemas agroalimentares; Alimentação adequada; Segurança alimentar e nutricional; Sustentabilidade.

\begin{abstract}
The hegemonic development in the field, which today is defined by the ideological matrix of agribusiness, is based mainly on monoculture and the use of pesticides, with the objective of increasing food production with the discourse of meeting the demand for the world population. However, several problems arose due to this logic of production, such as irreversible damage to the environment, problems in human health, losses in the field, food waste, among others. Considering this context, reflections, discussions and actions aimed at the conservation of the environment are growing in society, and an important tool for raising awareness in favor of the rational use of resources present in nature is Environmental Education. Through this, it is possible to provide the articulation between different areas of knowledge, in order to take knowledge and reflections, present experiences and raise awareness about the need to preserve, conserve and recover areas, among many other aspects related to the relationship established between human beings and the nature. In this perspective, this article aimed to analyze how Environmental Education can contribute to the promotion of healthy eating, pointing out the reflexes of the food production process in sustainable development. Thus, a literature review on Food Education and Healthy Eating was carried out. The results of the studies were analyzed, providing a synthesis on the subject in
\end{abstract}


question. It was found that some authors point to the success of Environmental Education as an instrument to sensitize people to an ecological spirit, therefore, it is an important instrument in an attempt to minimize the negative impacts resulting from food.

Keywords: Agri-food systems; Adequate food; Food and nutrition security; Sustainability.

\section{Resumen}

El desarrollo hegemónico en el campo, que hoy se define por la matriz ideológica de la agroindustria, se basa principalmente en el monocultivo y el uso de plaguicidas, con el objetivo de incrementar la producción de alimentos con el discurso de atender la demanda de la población mundial. Sin embargo, surgieron varios problemas debido a esta lógica de producción, como daños irreversibles al medio ambiente, problemas en la salud humana, pérdidas en el campo, desperdicio de alimentos, entre otros. En este contexto, las reflexiones, discusiones y acciones encaminadas a la conservación del medio ambiente están creciendo en la sociedad, y una importante herramienta de sensibilización a favor del uso racional de los recursos presentes en la naturaleza es la Educación Ambiental. A través de esto, es posible brindar la articulación entre diferentes áreas del conocimiento, con el fin de tomar conocimientos y reflexiones, presentar experiencias y concienciar sobre la necesidad de preservar, conservar y recuperar áreas, entre muchos otros aspectos relacionados con la relación que se establece entre los seres humanos. y la naturaleza. En esta perspectiva, este artículo tuvo como objetivo analizar cómo la Educación Ambiental puede contribuir a la promoción de una alimentación saludable, señalando los reflejos del proceso de producción de alimentos en el desarrollo sostenible. Así, se realizó una revisión de la literatura sobre Educación Alimentaria y Alimentación Saludable. Se analizaron los resultados de los estudios, proporcionando una síntesis sobre el tema en cuestión. Se encontró que algunos autores señalan el éxito de la Educación Ambiental como un instrumento para sensibilizar a las personas hacia el espíritu ecológico, por lo que es un instrumento importante en un intento de minimizar los impactos negativos derivados de la alimentación.

Palabras clave: Sistemas agroalimentarios; Alimentación adecuada; Seguridad alimentaria y nutricional; Sustentabilidad.

\section{Introdução}

O homem precisa garantir a integridade e a manutenção da biodiversidade do planeta, de modo que os recursos naturais presentes na mesma, estejam disponíveis de forma que 
garanta o direito das gerações futuras de também utilizá-los para suprir suas necessidades e uma saudável qualidade de vida. Para isso, diversos procedimentos e práticas devem ser adotados para o uso sustentável desses elementos da natureza.

Dentre as diferentes atividades econômicas que contribuem para possível degradação e desequilíbrio ambiental, está a produção de alimentos, que no Brasil, com a Revolução Verde, foi estabelecida uma lógica de agricultura baseada no modo de produção industrial para o cultivo de algumas espécies, com objetivo no aumento da produção e produtividade, e para tal, lançou-se mão de um conjunto de práticas tecnológicas, como a mecanização agrícola e utilização de insumos industriais, a exemplo dos fertilizantes químicos, agrotóxicos, desmatamentos, redução da biodiversidade funcional nos agroecossistemas, sementes geneticamente modificadas e uso intensivo de máquinas no preparo do solo (Jardim et al., 2009, Oliveira et al., 2020).

Esse modelo de produção agrícola vem acarretando em danos ao meio ambiente e problemáticas sociais como: perda da fertilidade do solo, redução da mão-de-obra, exclusão da agricultura familiar, progressiva resistência de insetos e pragas aos produtos químicos, poluição das águas, redução da agrobiodiversidade materializada pelo monocultivo, erosão, entre outros, além disso, contribuem significativamente para diversos problemas a saúde humana advindos pela contaminação do ambiente e dos alimentos, também é importante ressaltar que aliados a esse contexto, ocorrem perdas de alimentos ainda no campo ou no transporte dos mesmos (Luzzardi, 2006, Jardim et al., 2009, Oliveira et al., 2020). Böhm et al. (2017) destacam ainda que para a produção de alimentos é necessário a disponibilidade de recursos minerais do solo, de água e de luz, que podem ter disponibilidade afetada nos moldes de agricultura que adotam esses parâmetros mencionados.

Em relação a sociedade contemporânea e o consumo, é comum tanto no preparo e após servido, o desperdício de alimentos, que vão para o lixo e também o consumo de alimentos não saudáveis que são produzidos sob a lógica agroquímica e/ou os ultraprocessados (Cardoso \& Vieira, 2019). E Muitas vezes, essa realidade é despercebida pela grande maioria dos consumidores, seja pela facilidade na aquisição desses alimentos e de seu preparo, ou ainda pela falta de informação.

Vasques \& Messeder (2020) destacam que a humanidade, na busca pelo desenvolvimento e avanço tecnológico se distanciou da natureza, no qual, com o modelo vigente da sociedade capitalista, estabeleceu uma relação de domínio dos recursos naturais, e para mudar essa realidade mundial, que se baseia no individualismo em detrimento ao bemestar coletivo e que não leva em consideração os direitos e necessidades das futuras gerações, 
é fundamental investir no processo educativo da sociedade, desde de concepções educacionais até a formação humana.

Considerando esse contexto, destaca-se a Educação Ambiental como um importante instrumento que pode contribuir para sensibilização em prol da utilização racional do meio ambiente visando preservar, conservar e recuperar áreas, além disso, também na conscientização da importância da alimentação saudável, por meio da articulação entre diferentes áreas do conhecimento.

Segundo a legislação brasileira, educação ambiental é entendida como:

"[...] os processos por meio dos quais o indivíduo e a coletividade constroem valores sociais, conhecimentos, habilidades, atitudes e competências voltadas para a conservação do meio ambiente, bem de uso comum do povo, essencial à sadia qualidade de vida e sua sustentabilidade" (Brasil, 1999).

“A Educação Ambiental é uma dimensão da educação, é atividade intencional da prática social, que deve imprimir ao desenvolvimento individual um caráter social em sua relação com a natureza e com os outros seres humanos, visando potencializar essa atividade humana com a finalidade de torná-la plena de prática social e de ética ambiental" (Mec, 2012, art. $2^{\circ}$ ).

Sendo assim, o processo educativo com ênfase na Educação Ambiental, pode ser uma ferramenta de importante potencial na conscientização crítica sobre os inúmeros fatores e circunstâncias que acarretam em problemas ambientais, no aumento da desigualdade social e no comprometimento da qualidade de vida (Vasques \& Messeder, 2020). Portanto, pode ser uma aliada à produção sustentável e consumo de alimentos saudáveis.

Isto posto, este artigo teve como objetivo analisar como a Educação Ambiental pode contribuir no processo de alimentação saudável, visando apontar os reflexos do processo de produção alimentar no desenvolvimento sustentável.

\section{Metodologia}

A pesquisa realizada constituiu de uma revisão narrativa de caráter descritivo (Rother, 2007, Roman, et al., 2017, Pereira et al., 2018), sobre as contribuições da Educação Ambiental no processo de alimentação saudável, e a relação da produção de alimentos no desenvolvimento sustentável.

A coleta de dados em busca de informações relacionadas a temática desta pesquisa foi realizada entre setembro a novembro de 2020, que foram consultadas nas bases de dados 
Scientific Electronic Library Online (SciELO) e Google Acadêmico por meio de artigos, livros, anais, monografias, dissertações e teses, também foram consultados sites do governo federal do Brasil para obtenção de dados referente as normativas e leis, assim, as informações foram buscadas em sites do planalto do governo federal, ministério do meio ambiente, ministério da saúde e ministério da educação. Os trabalhos selecionados priorizaram experiências brasileiras, além disso, as referências dos trabalhos consultados na temática da pesquisa foram verificadas com a finalidade de identificar outros trabalhos que atendessem aos critérios de inclusão e que não houvessem sido localizados nas bases de dados consultadas.

Após a seleção dos trabalhos conforme a temática deste trabalho, seguiu-se os seguintes passos conforme Roman et al. (2017): leitura exploratória, leitura seletiva e escolha do material que contemplasse os objetivos desta pesquisa, análise dos textos e, por último, a realização de leitura interpretativa e redação (Roman, et al., 2017) propiciando uma síntese sobre a temática em questão, sem a pretensão de esgotar a discussão neste artigo.

\section{Considerações sobre Educação Ambiental}

A Educação Ambiental foi marcada historicamente pelas conferências de Estocolmo, do Rio de Janeiro e de Joanesburgo. Desde 1962, já se constava preocupação com meio ambiente, quando Rachel Carson em seu livro "Primavera Silenciosa", de 1962, advertiu para o perigo que o uso de substâncias químicas usadas nos processos produtivos traria para o meio ambiente (Souza \& Benevides, 2005). Produção que, no decurso do século XX, se consagrou como alvo a ser combatido pelo movimento ambientalista e ecologista em todo o mundo (Lemos et al., 2017a).

Em 1972, a Conferência das Nações Unidas sobre o Meio Ambiente Humano, realizada em Estocolmo, foi a primeira grande assembleia formada pelas Nações Unidas para tratar sobre problemas da natureza, em decorrência das insatisfações de vários segmentos da sociedade relacionadas à poluição do ambiente diante da qualidade de vida dos povos (Lago, 2006).

Em 1975, em atenção às orientações da Conferência de Estocolmo, a Organização das Nações Unidas para a Educação, Ciência e Cultura - UNESCO proporcionou em Belgrado (Iugoslávia) um Encontro Internacional em Educação Ambiental que constituiu o Programa Internacional de Educação Ambiental - PIEA, estabelecendo as seguintes normas 
orientadoras: a Educação Ambiental deve ser contínua, multidisciplinar, adaptada às diversidades regionais e dirigida para os interesses nacionais (Souza \& Benevides, 2005).

No Brasil, em 1987, o Plenário do Conselho Federal de Educação aprovou a incorporação da Educação Ambiental para o ensino, hoje, fundamental e médio e aconselhou a criação de Centros de Educação Ambiental (Buczenko, 2018).

Em 1988, a Constituição Federal Brasileira dispôs sobre o direito ao meio ambiente ecologicamente equilibrado (Brasil, 1988). Em 1991, o Ministério da Educação - MEC instituiu a Portaria 678/1991, estabelecendo que a Educação Ambiental fizesse parte nos ensinos escolares nos diversos graus de ensino (Mec, 1999).

Em 1992, aconteceu a Conferência das Nações Unidas sobre Meio Ambiente e Desenvolvimento, conhecida como a Conferência do Rio-92 - Eco-92, durante a qual a definição de desenvolvimento sustentável ficou consagrada, e possibilitou vasta conscientização de que os países desenvolvidos tinham responsabilidade sobre os prejuízos ao meio ambiente (Lago, 2006).

Em 1996, a Educação Ambiental foi definida como um dos propósitos fundamentais da esfera de Meio Ambiente, por meio da Lei nº 9.276/1996 (Brasil, 1996), ao prever ações como divulgação e uso de conhecimento sobre tecnologias de gestão sustentável dos recursos naturais.

Em 1999, foi estabelecida a Política Nacional de Educação Ambiental - PNEA a partir da publicação da Lei n 9.795, de 27 de abril de 1999 (Brasil, 1999). De acordo com Machado et al. (2006), a PNEA não possui a intenção de punir, mas sim de estimular ações que visem mudança no padrão de comportamento das relações humano-ambiente. Isso porque essa política possibilitou o desenvolvimento de atividades educacionais para a sensibilização do uso sustentável de recursos naturais, principalmente no ensino formal (Lemos et al., 2017b).

Em 2002, a Conferência de Joanesburgo conseguiu se organizar a despeito de vários entraves ocorridos anteriores a sua realização obtendo desenvolvimentos positivos. Vários dos acordos feitos no Rio de Janeiro foram levados a efeito devido ao esforço de populações e governos locais, estabelecimentos e entidades não governamentais, indicando que a concepção de desenvolvimento sustentável pode ter consequências sobre as pessoas (Lago, 2006).

Assim, em 2012, o MEC estabeleceu as Diretrizes Curriculares Nacionais para a Educação Ambiental a partir da Resolução no 2, de 15 de junho de 2012 (Mec, 2012). De acordo com a resolução, a Educação Ambiental permitiria "[...] ao desenvolvimento individual um caráter social em sua relação com a natureza e com os outros seres humanos, 
visando potencializar essa atividade humana com a finalidade de torná-la plena de prática social e de ética ambiental" (Mec, 2012, art. $2^{\circ}$ ).

Adams (2012) acrescenta que se trata de um procedimento educacional direcionado à conservação do ambiente, que apresenta diferenciados enfoques e um vasto número de entendimentos, e seu percurso começou a partir da década de 1970. A autora destaca ainda que a ausência de conhecimentos teóricos a respeito da Educação Ambiental, erroneamente leva a um entendimento de que se trataria de estudo da Ecologia, até da matéria de Ciências.

A escola que pratica Educação Ambiental como forma de sensibilizar seus discentes para proteger o meio ambiente deve despertar neles uma convivência em equilíbrio com o espaço em que vive (Silva et al., 2020). Para isso, a Educação Ambiental deve articular a temática ambiental entre os componentes curriculares, sendo, então, prática educativa integrada e interdisciplinar, contínua e permanente ao longo da formação do educando (Pereira et al., 2020).

Gomes \& Martins (2020), destacam que as gerações contemporâneas já nascem com um grande desafio para humanidade, a busca da sustentabilidade em suas ações e que além disso, torna-se necessário reconhecer que a relação estabelecida entre ser humano e natureza sempre foi muito complexa e que ao longo da evolução humana foi se alternando entre dominar e conservar o meio ambiente

Segundo Ploeg (2008), dois grupos de produção agrícola se enquadram nesse contexto, a agricultura empresarial que é baseada no uso de crédito, insumos industriais e tecnologias, sua expansão ocorre basicamente pelo aumento de escala e tem sua produção totalmente voltada para o mercado e a agricultura capitalista ou corporativa que segue um modelo agroexportador e envolve uma rede de empresas agrícolas de grande mobilidade, assim como, mão-de-obra baseada em trabalho assalariado e a produção destinada à maximização do lucro.

O autor supracitado destaca que esses grupos estão centralizados por grandes empresas de processamento e comercialização de alimentos, com atuação global, que ele classifica como impérios alimentares ou impérios agroalimentares, este último denominado por Facco (2015). Esses grupos se configuram por serem dominantes e normalmente abrangem grupos de empresários que são vinculados ao agronegócio, grandes varejistas, Estado, leis, modelos científicos e tecnologias, que direcionam os regimes alimentares presentes no mundo, no qual o controle da industrialização dos alimentos se dá por poucas empresas multinacionais, e que os alimentos se tornam cada vez mais um meio para obtenção de lucros (Ploeg, 2008, Facco 2015). 
Assim, no Brasil, o avanço do agronegócio para produção de alimentos vem acarretando em sérios problemas de degradação ambiental, reflexo do contexto exposto por Ploeg e Facco, há o consumo desmedido e o desperdício de alimentos e outros produtos obtidos por esse modo de produção, que não consideram os princípios do desenvolvimento sustentável. Portanto, a Educação Ambiental deve ser aliada para a conservação ambiental, mas está longe de ser exercida a contento (Bortolon \& Mendes, 2014). Por exemplo, se fossem priorizadas ações de educação ao consumidor, poderia ser esperado um consumo mais consciente e com menor desperdício de alimento, o que implicaria também em possíveis mudanças no nível da propriedade produtora de alimento (Lindgren et al., 2018).

Além disso, conforme colocado por Gomes \& Martins (2020), é importante frisar que a Educação Ambiental parte da premissa da participação social, uma parte essencial da política de proteção do meio ambiente e da política ambiental, no qual a percepção ambiental pode ser definida como uma tomada de consciência do ambiente pelo ser humano, ou seja, o ato de perceber o ambiente que se está inserido, aprendendo a proteger e a cuidar do mesmo, como da sociedade nele inserido

\section{Alimentos e Alimentação Saudável}

A sustentabilidade ambiental dos sistemas alimentares deve estar associada às ações com indivíduos ou grupos sobre suas escolhas alimentares e na orientação de alimentação nacional, de modo que se tenha melhoras na saúde nutricional da população (Rose et al., 2019).

Porém, a mercantilização dos alimentos aumentou a distância cada vez mais entre a produção e o consumo de uma comunidade, já que a mediação entre a produção e o consumo passou a ser realizada por empresas que necessitam de alimentos mais duráveis e de melhor escoamento da produção, no qual, os países em desenvolvimento através de monocultivos para produção de commodities contribuíram para a produção de alimentos baratos e abundantes, o que refletiu na diminuição da autossuficiência alimentar, aumento nas dívidas externas, além de tensões entre a demanda de alimentos e a produção (Triches \& Schneider, 2015).

Outro aspecto, referido por Martinelli e Carvalli (2019), é a produção animal, que pode contribuir com a emissão de gases danosos ao efeito estufa, abertura de grandes áreas para o pastejo dos animais e grande consumo de soja e milho para a nutrição dos animais. Almeida et al. (2017) mostram que soja, milho e algodão são as espécies geneticamente 
modificadas cultivadas no Brasil, e que ao se analisar o cultivo dessas espécies geneticamente modificadas e uso de agrotóxicos por cultura, somente as três espécies concentraram $65 \%$ do consumo total de agrotóxico utilizado, e a soja, predominante entre as geneticamente modificadas, contribuiu para $71 \%$ desse volume.

Botelho et al. (2020) ao analisarem os danos, as consequência e a poluição causados pelo uso dos agrotóxicos na agricultura brasileira e os impactos ambientais diretos e indiretos provocados pela utilização contínua desses agroquímicos, relatam que o consumo de agrotóxicos cresceu bastante nas últimas décadas, e o país tornou-se um dos líderes mundiais no consumo de agrotóxicos, e destacam que o principal meio de absorção do agrotóxico no ser humano é por meio da pele, seja pela falta de proteção ou uso incorreto do equipamento de proteção individual.

O autores supracitados, destacam ainda, que uma das doenças que pode ser relacionada com uso de agrotóxico de forma cumulativa no organismo é o câncer, também relatado em trabalho realizado por Sousa et al. (2020) ao realizar um levantamento e analisar publicações científicas sobre os impactos ocasionados pelo uso de agrotóxicos no Brasil, que também mencionaram a ocorrência de malformação congênita relacionada ao uso desses produtos.

Botelho et al. (2020) também informam que as classes de agrotóxicos mais utilizados são os herbicidas, inseticidas e fungicidas que são altamente prejudiciais para a saúde humana, e enfatiza que no Brasil será autorizado o uso de agrotóxicos, anteriormente proibidos pelos órgãos regulatórios, pois são comprovadamente tóxicos para organismos vivos e que a diminuição dos preços desses produtos mais tóxicos e a isenção de alguns tributos, também acarretam no aumento da quantidade utilizada, expondo a população às maiores cargas químicas, além da exposição múltipla às diversas classes de uso e tipos de agrotóxicos.

Sendo assim, percebe-se algumas das problemáticas ambientais e de saúde que são resultado do contexto da agricultura mercantilista que se estabeleceu no Brasil, além disso, também afeta a qualidade dos alimentos que são consumidos pela população brasileira. Nesse sentido, Gomes \& Frinhani (2017) citam como objetivo de ter benefícios à saúde, o consumo de alimentos orgânicos, uma vez que a produção deles não usa produtos que sejam agressivos à saúde e nem à natureza. A respeito disso, enfatiza-se que a ausência de substâncias como defensivos agrícolas, quais sejam, inseticidas, herbicidas, fungicidas, bactericidas, agentes nocivos à saúde e ao meio ambiente, notadamente influenciará na qualidade do alimento e na conservação do ar, do solo, da água. 
No Brasil, é assegurado ao cidadão brasileiro o direito à alimentação e à saúde, dentre ouros, garantidos pela Constituição da República Federativa do Brasil (CRFB) de 1988, em seu Art. $6^{0}$ (Brasil, 1988): "São direitos sociais a educação, a saúde, a alimentação, o trabalho, a moradia, o transporte, o lazer, a segurança, a previdência social, a proteção à maternidade e à infância, a assistência aos desamparados, na forma desta Constituição" (Brasil, 1988).

Alimento é um meio para, além de satisfazer a fome, melhorar a saúde e proporcionar prazer e bem-estar (Nitzke et al., 2012). No que concerne à insegurança alimentar e nutricional, Ferreira (2010) explica que é desenhada por várias situações, como ausência do que comer grandes, ingestão de quantidades de elementos prejudiciais ao organismo, ou privação de certos nutrientes, pela ingestão de alimentos com agrotóxicos e/ou estragados, e geneticamente modificados, desconhecimento sobre o produto e outros falta de emprego. Assim, deduz-se que não basta a disponibilidade do alimento, se ele não for de boa qualidade e em quantidades suficientes para nutrir o indivíduo.

Entende-se, portanto, que quando o alimento não é contemplado, nem em quantidade, nem em qualidade que o organismo precisa para se manter saudável, caso dos mais vulneráveis socioeconomicamente, isso poderá ter reflexos negativos na saúde.

Quanto ao Direito Humano à Alimentação, Gomes \& Frinhani (2017) reportam que o homem só terá desfrute de todos seus direitos humanos, se estiver livre da fome e tiver alimentação adequada. Sobre isso, convém destacar que grande número de pessoas no Brasil ainda não tem o que comer. A desigualdade social muitas vezes não assegura uma completa refeição diária, tampouco uma refeição saudável. Aliado a isso, muitas pessoas sequer sabem o significado pleno de alimentação saudável.

Uma alimentação saudável é composta de produtos alimentares que têm balanço nutricional. Para a Organização Mundial de Saúde, uma alimentação saudável ajuda a combater a desnutrição em todas as suas formas, e deve começar no início da vida, desde a amamentação, esperando-se ter crescimento saudável e desenvolvimento cognitivo, com benefícios à saúde a longo prazo (WHO, 2020).

Em pesquisa sobre "Hábitos Alimentares e Sustentabilidade: Percepções e Vivências de Alunos do ensino Fundamental”, Scheunemann et al. (2018) não encontraram qualquer resposta direcionada ao valor de se debater sobre alimentação no âmbito de questões que envolvam sua produção. Com isso, os autores detectaram uma fragilidade no conhecimento dos alunos sobre o assunto.

Ora, hoje não se deve aceitar falta de conhecimento sobre a produção de alimentos, que impactam o meio ambiente e também afetam a saúde do ser humano, nesse sentido, a 
legislação Brasileira obriga, desde 2005, que alimentos e ingredientes alimentares destinados ao consumo humano ou animal devem informar em seus rótulos se possuem ou foram produzidos a partir de organismos geneticamente modificados (Brasil, 2005).

Portanto, estratégias inteligentes e sensatas precisam nortear a alimentação das pessoas e o conhecimento sobre a produção e origem dos alimentos que consomem, desde a infância até a vida adulta. Se isso não ocorre, como crianças, jovens e adultos poderão contribuir com o desenvolvimento sustentável se desconhecem a importância do assunto?

No que se refere à Alimentação Saudável, é a garantia ao acesso permanente e regular, de modo a ser socialmente justa, considerando aspectos biológicos e sociais do indivíduo, bem como deve estar em sintonia com possíveis necessidades alimentares especiais (Marconato et al., 2016).

Institucionalmente, para o Ministério da Saúde "alimentação adequada e saudável é a prática alimentar apropriada aos aspectos biológicos e socioculturais dos indivíduos, bem como ao uso sustentável do meio ambiente"; e ser alcançável sob a perspectiva física e financeira, ser condizente em qualidade e quantidade, estar assentada em ações produtivas apropriadas e sem prejuízo ao meio ambiente (Brasil, 2015, p.31).

A condição social tem influência na maneira de viver das pessoas, tendo como efeito, maneiras injustas de alcance à alimentação que é uma necessidade vital. As camadas social e economicamente dominadoras fazem parte de um grupo intelectualizado e que têm alcançabilidade a alimentos cujos preços de mercado são altos (Minuzi \& Pommer, 2019).

Muitas vezes o consumidor é induzido ao alimento que não é salutar, que podem acarretar enfermidades. Os meios de comunicação apresentam o alimento de modo chamativo, relacionando-o à satisfação, sem que haja ponderação a respeito de seus constituintes e/ou valor nutricional (Minuzi \& Pommer, 2019). Nesse momento destaca-se a importância da Educação Ambiental, pois, ela pode despertar a percepção que costumes alimentares saudáveis podem promover boa qualidade de vida, e podem ter influência positiva na conservação da natureza.

Muitos trabalhos sobre Educação Ambiental têm sido direcionados para a mudança no meio ambiente originada pelo homem durante o processo de produção do alimento, a despeito da sua extensão conceitual. Quando alteração gera um desequilíbrio ecológico, ela causará um impacto negativo. Um exemplo é o mencionado acima, a liberação de gases, o efeito estufa, observado nas culturas de animais. Por outro lado, a diminuição desses gases e, portanto, redução de dano ao ambiente, não significa que o alimento será sustentável se ele vier causar agravos à saúde do homem em qualquer momento de seu percurso, enquanto alimento. 
Martinelli \& Cavalli (2019) fazem a seguinte consideração:

"Para que seja possível a concretização de um sistema mais sustentável, é necessário que a população tenha acesso a distintas formas de produção, processamento e comercialização. Dessa forma, salienta-se a intervenção do Estado nas políticas alimentares como fator essencial para a consolidação da alimentação sustentável. Na perspectiva do consumo, considera-se fundamental a indissociabilidade entre a promoção da alimentação saudável e sustentável e que as premissas de ambas sejam articuladas e consideradas em recomendações alimentares" (p. 4258).

\section{Contribuições da Educação Ambiental a Produção Alimentar Sustentável}

A questão ambiental envolve aspectos que demandam tempo e também necessitam de reflexões e pesquisas transdisciplinares para se conseguir determinadas respostas e escolhas com densidade. O ofício de gerar saberes, no sentido da sustentabilidade, no âmbito da Educação Ambiental, está atrelado aos impactos e escolhas que viabilizem a formação de uma comunidade igualitária, e socialmente justa e que não cause qualquer dano ambiental (Reigota, 2007). Isso colocado vem à luz que, por questão econômica, o ser humano muitas vezes injuria o ambiente, causando desarmonia entre os componentes do meio natural, com reflexos no equilíbrio ecológico e na saúde da humanidade. Portanto, é imperioso que o homem use os recursos naturais de maneira sábia, racional e com habilidade.

Constata-se ser amplo o campo de contribuição da Educação Ambiental. Dessa forma, cita-se o trabalho de Pereira et al. (2018), que estudarem a Educação Ambiental no processo de gestão ambiental - licenciamento ambiental de petróleo e gás na Bacia de Campos, mencionam que não há uma ação que não cause algum tipo de abalo, seja ele na dinâmica da comunidade, como no espaço físico-natural. Após terem conhecimento de como ocorreu todo o processo do citado licenciamento, elas recomendam:

"A educação é articulada com a vida e a transformação social, sendo o ato cognoscente um processo de autopercepção do sujeito no mundo em que se encontra. Um perceber-se e um encontrar-se no mundo, com o mundo e com os outros, através da capacidade comunicativa, pelo diálogo" (Pereira et al. 2018, p. 13).

Silva et al. (2020), em seu trabalho com horta escolar, verificaram que técnicas agroecológicas usadas, em contraposto ao padrão convencional, possuem potencialidade na obtenção de alimentos orgânicos, o que assegura conservação do local usado para a horta. 
A fim de conhecer as representações sociais de problemas ambientais sob a ótica de docentes que atuam na cidade de Castanhal - Pará, Andrade (2018) cita que professores destacaram algumas preocupações, deixadas em segundo plano, como ter saúde quando se consome alimentos produzidos em solos contaminados, ressaltando que ainda se gasta muito para se ter saúde e alimentos saudáveis. De acordo com a autora, os participantes da pesquisa mostram que a Educação Ambiental deve ser fortalecida como processo de luta e enfretamento da crise ambiental na Amazônia.

Em consideração ao resultado obtido por Scheunemann et al. (2018), é pertinente destacar que trabalhos de Educação Ambiental surtem efeitos positivos quando se trata de sustentabilidade. Para corroborar, Silva et al. (2016) relatam intervenção educativa com objetivo de diminuir o desperdício alimentar em uma unidade de alimentação que gerou algum êxito na ação dos autores, apesar de ainda ter havido desperdício.

Outro exemplo de comprometimento com a sustentabilidade é o trabalho de Cardoso et al. (2015), objetivando transformar um ex-lixão em espaço sustentável, desenvolveram ações como palestras, mobilização comunitária, oficinas, práticas agrícolas simples: preparação, implementação, manutenção da horta comunitária e do bosque de flores. Os autores tinham conseguido como ações bem-sucedidas, uma horta suspensa piloto em tubos de PVC adaptados, plantação de mudas de morango, oficinas com atividades de higienização, preparo de sabão líquido caseiro e de álcool a $70 \%$.

Segundo Nunes e Botelho (2009), o desconhecimento acerca das substâncias nutritivas e do aproveitamento dos alimentos causam a perda de toneladas de tipos alimentares. $\mathrm{O}$ aproveitamento integral dos alimentos é de suma importância porque impede o desperdício e aumenta o valor nutricional da alimentação. A quantidade de pessoas que recorre ao aproveitamento integral dos alimentos é muito pequena.

Além disso, ações de Educação Ambiental podem contribuir para minimizar os desperdícios de alimentos, que de acordo com Storck et al. (2013), partes dos alimentos, usualmente descartadas, podem servir de preparo de várias receitas, o que gera também economia às famílias.

Outro exemplo de redução dos desperdícios de alimentos é ilustrado por Cardoso e Vieira (2019), ao estudar o caso do Programa Mesa Brasil (SESC) na cidade de Santarém, Pará. Os autores mostraram que por meio da sensibilização de feirantes de uma feira tradicional da cidade, em seis meses de observação, foi possível levantar a doação de 34.513 $\mathrm{kg}$ de alimentos que seriam jogados no lixo, e dessa forma beneficiaram mais de 21.000 pessoas nessa cidade. 
A produção de alimentos nas cidades se dá também por meio das árvores e plantas cultivadas no espaço urbano. Ao estudar o papel da arborização urbana na Amazônia, Vieira e Panagopoulos (2020) propõem que por meio de ações de Educação Ambiental a sociedade pode conhecer o papel da infraestrutura verde urbana, que inclui a produção de alimentos, tais como frutos. Segundo os autores, essas ações podem contribuir para a conservação ambiental no espaço urbano na Amazônia brasileira. Além disso, pode-se compreender que a vegetação urbana pode ser importante fornecedora de alimentos nas cidades.

No contexto amazônico, Clement \& Higuchi (2006) mostram que educação sobre alimentação da região, ainda é deficiente no país e na própria região, e destacam que a Educação Ambiental é igualmente deficitária ao não valorizar o papel floresta, por exemplo, no ensino formal, e sugerem que o ministério da Educação revise as grades curriculares de primeiro grau à universidade, com vistas a refletir sobre o papel de uma agricultura sustentável na região.

\section{Considerações Finais}

Entende-se que o ato de se alimentar de forma saudável faz referência a alimentos livres de substâncias de qualquer que seja sua natureza (químicos, biológicos e físicos) que possam originar prejuízos às pessoas. Por isso, tem que estar em consonância com a saúde da biodiversidade.

Ademais, um sistema de produção de alimentos deve visar o equilíbrio entre os segmentos ambiental, social, cultural e econômico. Desse modo, as instituições envolvidas no processo de geração de alimentos devem incentivar a conservação da diversidade biológica da natureza, saúde ambiental, dos animais e dos humanos.

Nesse seguimento, a Educação Ambiental configura-se como uma ferramenta fundamental para minimizar os estragos causados por ações insustentáveis. Ela pode contribuir por um pensar ecológico durante o processo produtivo do alimento. Para tal, ela tem que ser dinâmica e constante. Só assim, poderá haver transformação da sociedade no sentido de preservação e conservação do meio ambiente.

Por certo, na questão do alimento, a Educação Ambiental pode contribuir muito mostrando alternativas de plantação, colheita e consumo para evitar desperdícios que poderão impactar negativamente o meio ambiente.

No que tange o desperdício de alimentos, a Educação Ambiental é capaz de colaborar orientando, por exemplo, no aproveitamento de partes dos alimentos que geralmente são 
descartadas. Um trabalho educativo pode evitar que toneladas de alimentos sejam descartadas, já que grande parte do lixo é de origem orgânica o que evidencia uso inadequado dos alimentos.

A diminuição do desperdício de alimentos, que pode ocorrer desde o processo de produção, seguido pelo seu transporte, nos locais de venda (supermercados, feiras livres, restaurantes, lanchonetes e outros), deve ser trabalhada por ações da Educação Ambiental com o indivíduo ainda criança, época que é mais fácil de desenvolver nele uma consciência ambiental. Ela deve acontecer tanto no convívio familiar como nas escolas.

Ademais, por vezes o costume de alimentação inadequada é justificado por falta de tempo. Porém, na maioria das vezes, o hábito de se alimentar inadequadamente é por desconhecimento do que seja uma alimentação adequada e também por não conhecer os danos que ela pode causar ao meio ambiente. A humanidade precisa da natureza para sua existência e não zelar pelos recursos naturais é apostar em sua exaustão.

Salienta-se a necessidade de uma pesquisa de revisão sistemática sobre a temática trabalhada neste artigo, sugerindo-se a realização de biblometria ou cienciometria, com consultas de artigos científicos que apresentem experiências tanto a nível mundial quanto no âmbito das diversas regiões do Brasil, para que seja possível conhecer e refletir sobre pesquisas nacionais e internacionais, através de maior rigor metodológico, para ampliar as discussões que não se esgotaram neste artigo, mas que sim, apresentam um ponta pé inicial para refletir sobre uma temática de relevante importância para a saúde e qualidade de vida do ser humano.

\section{Referências}

Adams, B. G. (2012). A Importância da Lei 9.795/99 e das Diretrizes Curriculares Nacionais da Educação Ambiental para Docentes. Monografias Ambientais, 10(10), 2148-2157. https://doi.org/10.5902/223613086926

Almeida, V. E. S., Friedrich, K., Tygel, A. F., Melgarejo, L., \& Carneiro, F. F. (2017). Uso de sementes geneticamente modificadas e agrotóxicos no Brasil: cultivando perigos. Ciência \& Saúde Coletiva, 22(10), 3333-3339. https://doi.org/10.1590/1413-812320172210.17112017

Andrade, F. M. R. (2018). A Amazônia além das florestas, dos rios e das escolas: representações sociais e problemas ambientais. Ambiente \& Sociedade, 21, e00250. https://doi.org/10.1590/1809-4422asoc0250r1vu1813ao 
Böhm, F. M. L. Z., Böhm, P. A. F., Rodrigues, I. C., \& Santana Júnior, M. P. (2017). Utilização de hortas orgânicas como ferramenta para Educação Ambiental. Luminária, 19(1), 20-26.

Bortolon, B., \& Mendes, M. S. S. (2014). A importância da Educação Ambiental para o alcance da Sustentabilidade. Revista Eletrônica de Iniciação Científica, 5(1), 118-136.

Botelho, M. G. L., Pimentel, B. S., Furtado, L. G., Lima, M. C. S., Carneiro, C. R. O., Batista, V. A., Marinho, J. L. M., Monteiro, A. L. P. R., Silva, T. P., Pontes, A. N., \& Costa, M. S. S. (2020). Agrotóxicos na agricultura: agentes de danos ambientais e a busca pela agricultura sustentável. Research, Society and Development, 9(8), e396985806.

http://dx.doi.org/10.33448/rsd-v9i8.5806

Brasil. Constituição Federal do Brasil. (1988). Brasília: Congresso Nacional. Recuperado de: http://www.planalto.gov.br/ccivil_03/constituicao/constituicao.htm

Brasil. Lei 9.276, de 9 de maio de 1996. (1996). Brasília: Congresso Nacional. Recuperado de: http://www.planalto.gov.br/ccivil_03/LEIS/L9276.htm

Brasil. Lei 9.795, de 27 de abril de 1999. (1999). Brasília: Congresso Nacional. Recuperado de: http://www2.mma.gov.br/port/conama/legiabre.cfm?codlegi=321

Brasil. Lei 11.105 de março de 2005. Brasília: Congresso Nacional. Recuperado de:http://www.planalto.gov.br/ccivil_03/_Ato2004-2006/2005/Lei/L11105.htm.

Brasil. Ministério da Saúde. (2015). Guia Alimentar para a População Brasileira. Brasília: MEC. Recuperado de: http://bvsms.saude.gov.br/bvs/publicacoes/politica nacional_alimentacao_nutricao.pdf

Buczenko, G. L. (2018). Educação Ambiental e Educação do Campo: Caminhos em Comum. Curitiba: Appris. 235p. 
Cardoso, A. M. A., \& Vieira, T. A. (2019). Práticas de redução do desperdício de alimentos: o caso de um projeto social em Santarém, Pará. Multitemas, 24(58), 137-156. https://doi.org/10.20435/multi.v24i58.2515

Cardoso, E. R., Moreti, B. H. L., Carneiro, P. A. V., \& Silva, S. S. (2015). Ação Comunitária e Desenvolvimento Urbano: Transformação de um Ex-lixão em Espaço Sustentável. Revista online de Extensão e Cultura Realização, 2(4) 61-69.

Clement, C. R., \& Higuchi, N. (2006). A floresta amazônica e o futuro do Brasil. Ciência e Cultura, 58(3), 44-49.

Facco, V. A. (2015). Alternativas aos impérios agroalimentares a partir do campesinato agroecológico: as experiências do acampamento agroflorestal José Lutzenberger (MSTAntonina/PR). Revista NERA, 29.

Ferreira, M. G. (2010). Direito humano à alimentação adequada. 54p. 2010. Monografia (Especialização em Política e Representação Parlamentar). Câmara dos Deputados/Centro de Formação, Treinamento e Aperfeiçoamento, Brasília.

Gomes, C. V., \& Frinhani, F. M. D. (2017). Alimentação Saudável como Direito Humano à Saúde: uma Análise das Normas Regulamentadoras da Produção de Alimentos Orgânicos. Leopoldianum, 43(121).

Gomes, K. B. P., \& Martins, R. C. C. (2020). Educação e sustentabilidade no ambiente rural: um estudo de caso sobre a percepção de agricultores familiares. Research, Society and Development, 9(7), e507974429. http://dx.doi.org/10.33448/rsd-v9i7.4429

Jardim, I. C. S. F., Andrade, J. A., \& Queiroz, S. C. N. (2009). Resíduos de agrotóxicos em alimentos: uma preocupação ambiental global - Um enfoque às maçãs. Quím. Nova, 32(4), 996-1012. http://dx.doi.org/10.1590/S0100-40422009000400031

Lago, A. A. C. (2006). Estocolmo, Rio, Joanesburgo: O Brasil e as três Conferências Ambientais das Nações Unidas. Brasília: Funag. 
Lemos, P. B. S., Saldanha Neto, C. D., \& Xavier, A. R. (2017a). Origens e fundamentos legais da educação ambiental. Revista Âmbito Jurídico, 159(20). https://ambitojuridico.com.br/cadernos/direito-ambiental/origens-e-fundamentos-legais-daeducacao-ambiental/

Lemos, P. B. S., Saldanha Neto, C. D., \& Xavier, A. R. (2017b). A Política Nacional de Educação Ambiental (Lei n 9.795/1999) e a legalização da educação ambiental no ensino formal. Educação Ambiental em Ação, 16(60). http://revistaea.org/artigo.php?idartigo=2771

Lindgren, E., Harris, F., Dangour, A.D., Gasparatos, A., Hiramatsu, M., Javadi, F., Loken, B., Murakami, T., Scheelbeek, P., \& Haines, A. (2018). Sustainable food systems - a health perspective. Sustainability Science, 13, 1505-1517. https://doi.org/10.1007/s11625-018-0586$\mathrm{X}$

Luzzardi, R. E. S. (2006). Educação Ambiental: Sustentáculo para o desenvolvimento da agricultura sustentável. Rev. eletrônica Mestr. Educ. Ambient., 17, 52-70. https://doi.org/10.14295/remea.v17i0.3024

Machado, R. F. O., Garcia, F. C., \& Amim, V. (2006). O encontro da política nacional da educação ambiental com a política nacional do idoso. Saúde e Sociedade, 15(3), 162-169. https://doi.org/10.1590/S0104-12902006000300013

Marconato, M. S. F., Silva, G. M. M., \& Frasson, T. Z. (2016). Hábito alimentar de universitários iniciantes e concluintes do curso de nutrição de uma universidade do interior paulista. Revista Brasileira de Obesidade, Nutrição e Emagrecimento, 10(58), 180-188.

Martinelli, S. S., \& Cavalli, S. B. (2019). Alimentação saudável e sustentável: uma revisão narrativa sobre desafios e perspectivas. Ciência \& Saúde Coletiva, 24(11), 4251-4261. https://doi.org/10.1590/1413-812320182411.30572017

MEC. Ministério da Educação. Conselho Nacional de Educação. (2012). Resolução $n^{o}$ 2, de 15 de junho de 2012. Brasília: MEC. Recuperado de: http://portal.mec.gov.br/dmdocuments/rcp002_12.pdf. 
MEC. Ministério da Educação. (1999). Um pouco da História da Educação Ambiental. Brasília: MEC. Recuperado de: http://portal.mec.gov.br/secad/arquiv os/pdf/educacaoambiental/historia.pdf

Minuzi, G. A., \& Pommer, R. M. G. (2019). Reflexões iniciais sobre a alimentação das classes sociais. Revista Latino-Americana de Estudos em Cultura e Sociedade, 5, 1-11. http://dx.doi.org/10.23899/relacult.v5i4.1198

Nitzke, J. A., Thys, R., Martinelli, S., Oliveiras, L. Y., Augusto-Ruiz, W., Penna, N. G., \& Noll, I. B. (2012). Segurança alimentar - retorno às origens? Brazilian Journal of Food Technology, 15, 2-10. https://doi.org/10.1590/S1981-67232012005000044

Nunes, J. T., \& Botelho, R. B. A. (2009). Aproveitamento Integral dos Alimentos: Qualidade Nutricional e Aceitabilidade das Preparações. 64p. 2009. Monografia (Especialização em Qualidade em Alimentos), Universidade de Brasília, Brasília.

Oliveira, L. S., Pereira, A. I. S., Lopes Sobrinho, O. P., Craveiro, S. A., Xavier, R. S., \& Pereira, A. G. S. (2020). Práticas agroecológicas em hortas adotadas por agricultores familiares do campo agrícola fomento em Codó, Maranhão. Research, Society and Development, 9(6), e30963340. http://dx.doi.org/10.33448/rsd-v9i6.3340

Pereira, A. S., Shitsuka, D. M., Parreira, F. J. \& Shitsuka, R. (2018). Metodologia da pesquisa científica. Santa Maria: NTE. Recperado de: https://repositorio.ufsm.br/bitstream/h andle/1/15824/Lic_Computacao_Metodologia-Pesquisa-Cientifica.pdf?sequence=1

Pereira, C. R., Anello, L. F. S., \& Pereira, M. O. R. (2018). Educação ambiental no processo de gestão ambiental: algumas reflexões e possibilidades. RELACult - Revista LatinoAmericana de Estudos em Cultura e Sociedade, 4, e996. http://dx.doi.org/10.23899/relacult.v4i0.996

Pereira, K. B., Dinardi, A. J., \& Pessano, E. C. (2020). A abordagem da Educação Ambiental em um Projeto Pedagógico de um Curso de Ciências da Natureza. Research, Society and Development, 9(8), e101985200. http://dx.doi.org/10.33448/rsd-v9i8.5200 
Ploeg, J. D. (2008). Camponeses e impérios alimentares: lutas por autonomia e sustentabilidade na era da globalização. Porto Alegre: Editora UFRGS. 373p.

Reigota, M. A. S. (2007). Ciência e Sustentabilidade: a contribuição da educação ambiental. Revista de Avaliação da Educação Superior, 12(2), 219-232. https://doi.org/10.1590/S141440772007000200003

Ribeiro, H., Jaime, P. C., \& Ventura, D. (2017). Alimentação e sustentabilidade. Estudos Avançados, 31(89), 185-198. http://dx.doi.org/10.1590/s0103-40142017.31890016

Roman, C., Ellwanger, J., Becker, G. C., Silveira, A. D. da, Machado, C. L. B. \& Manfroi, W. C. (2017). Metodologias ativas de ensino-aprendizagem no processo de ensino em saúde no Brasil: uma revisão narrativa. Clin Biomed Res, 37(4), 349-357. http://dx.doi.org/10.4322/2357-9730.73911

Rose, D., Heller, M. C., \& Roberto, C. A. (2019). Position of the Society for Nutrition Education and Behavior: The Importance of Including Environmental Sustainability in Dietary Guidance. Journal of Nutrition Education and Behavior, 51(1), 3-15. https://doi.org/10.1016/j.jneb.2018.07.006.

Rother, E. T. (2007). Revisão Sistemática x Revisão Narrativa. Acta Pulista de Enfermagem, 20 (2). Recuperado de: https://www.redalyc.org/pdf/3070/307026613004.pdf

Scheunemann, C. M. B, Costa, R. D. A., Almeida, C. M. M., \& Lopes, P. T. C. (2018). Hábitos Alimentares e Sustentabilidade: Percepções e Vivências de Alunos do ensino Fundamental. In Anais, 3 Encontro de Ciências em Educação para a Sustentabilidade.

Silva, A. P. S., Santos, M. A., Spinelli, M. G. N., Matias, A. C. G., \& Coelho, H. D. S. (2016). Intervenção Educativa no Controle de Restos em Unidade de Alimentação e Nutrição. Revista da Universidade Vale do Rio Verde, 14(2), 319-327. http://dx.doi.org/10.5892/ruvrd.v14i2.2660

Silva, L. F., Barros, R. P., Pinheiro, R. A., Silva, J. E., Cabral, M. J. S., \& Lima, J. S. (2020). Agroecologia e horta escolar como ferramentas de educação ambiental e produção de 
alimentos naturais. Diversitas Journal, 5(1), 27-33. https://doi.org/10.17648/diversitasjournal-v5i1-1050

Sousa, A. D. M., Sousa, A. M. P., Alves, H. S., Vieira, T. A., Sousa, A. D. M., Sousa, A. D. M. (2020). Os impactos do uso de agrotóxicos no Brasil: uma análise cienciométrica. Cadernos de Agroecologia, 15(2).

Souza, J. N. S., \& Benevides, R. C. A. (2005). Educação Ambiental Para o Desenvolvimento Sustentável e o Comprometimento das Universidades/Faculdades do Município do Rio de Janeiro, RJ. In Anais, 2 Simpósio de Excelência em Gestão e Tecnologia - SEGeT’. (pp. 531548). Resende: AEDB. Recuperado de: https://www.aedb.br/seget/arqui vos/artigos05/343_artigo.pdf

Storck, C. R., Nunes, G. L., Oliveira, B. B., \& Basso, C. (2013). Folhas, talos, cascas e sementes de vegetais: composição nutricional, aproveitamento na alimentação e análise sensorial de preparações. Ciência Rural, 43(3), 537-543. https://doi.org/10.1590/S010384782013000300027

Vasques, C. C., \& Messeder, J. C. (2020). Educação Ambiental em uma perspectiva reflexiva na Educação de Jovens e Adultos. Research, Society and Development, 9(8), e113984782. http://dx.doi.org/10.33448/rsd-v9i8.4782

Vieira, T. A., \& Panagopoulos, T. (2020). Urban forestry in Brazilian Amazonia. Sustainability, 12, 3235. https://doi.org/10.3390/su12083235

WHO - World Health Organization. (2020). Healthy diet. Recuperado de: https://www.who.int/news-room/fact-sheets/detail/healthy-diet. 
Research, Society and Development, v. 9, n. 12, e45691211237, 2020

(CC BY 4.0) | ISSN 2525-3409 | DOI: http://dx.doi.org/10.33448/rsd-v9i12.11237

Porcentagem de contribuição de cada autor no manuscrito

Lorena Almeida Vieira - 30\%

Maria Mirtes Cortinhas dos Santos - 25\%

Thiago Almeida Vieira - 25\%

Jorgiene dos Santos Oliveira - 5\%

Helionora da Silva Alves - 15\% 